\title{
Missing temporal effects of soil insecticides and entomopathogenic nematodes in reducing the maize pest Diabrotica virgifera virgifera
}

\author{
Szabolcs Toth ${ }^{1} \cdot$ Mark Szalai $^{1} \cdot$ Jozsef Kiss ${ }^{1} \cdot$ Stefan Toepfer ${ }^{1,2}$ \\ Received: 15 July 2019 / Revised: 27 October 2019 / Accepted: 16 December 2019 / Published online: 14 January 2020 \\ (c) The Author(s) 2020
}

\begin{abstract}
Control methods for the larvae of the maize pest Diabrotica virgifera virgifera (Coleoptera: Chrysomelidae) are known to produce inconsistent results under field conditions. To better understand the effects of plant protection products on the rootfeeding larvae, we looked for changes in efficacy of the granular soil insecticides chlorpyrifos, cypermethrin, and tefluthrin during a cropping season, as well as a fluid-applied entomopathogenic nematode Heterorhabditis bacteriophora (Rhabditida: Heterorhabditidae). Twelve field-scale experiments carried out in Hungary between 2010 and 2018 revealed that treatments, whether chemical or biological, are able to reduce D. v. virgifera. However, results were variable with failures in about a quarter of the experiments. Unexpectedly, our findings indicated only limited effect of time on treatments, meaning all products appeared capable of continuously reducing larvae during their time in the soil. Only chlorpyrifos seemed to slightly lose and tefluthrin to slightly increase efficacy over time. Nevertheless, there is no major evidence that failure of treatments is due to temporal effects. Other factors may play a larger role and merit investigation under field conditions.
\end{abstract}

Keywords Western corn rootworm $\cdot$ Zea mays $\cdot$ Chlorpyrifos $\cdot$ Cypermethrin $\cdot$ Tefluthrin $\cdot$ Heterorhabditis bacteriophora . Pest control

\section{Key message}

- The western corn rootworm is a maize pest in North America and Europe.

- Chemical and biological control of its root-feeding larvae is often variable.

- We hypothesized that soil insecticides lose and beneficial nematodes increase their efficacy with time.

Communicated by C.M. Benefer.

Mark Szalai

szalai.mark@mkk.szie.hu

Szabolcs Toth

toth.szabolcs.8@phd.uni-szie.hu

Jozsef Kiss

jozsef.kiss@mkk.szie.hu

Stefan Toepfer

s.toepfer@cabi.org

1 Plant Protection Institute, Szent Istvan University, Pater Karoly utca 1, 2100 Godollo, Hungary

2 CABI, Rue des Grillons 1, 2800 Delémont, Switzerland
- We analysed temporal effects of treatments in 12 Hungarian fields over 7 years.

- Treatments led to variable results with failures in about a quarter of the experiments.

- Findings indicated only limited effect of time on treatments.

- Other factors may play a larger role and merit investigation under field conditions.

\section{Introduction}

Maize is one of the three major carbohydrate providers to humans next to rice and wheat. In the European Union, maize ranks second after wheat with around 65 million tonnes grain maize and maize-cob-mix harvested in 2017 (Cook 2018). In the USA, maize ranks second after soybean with around 400 million tons grain maize harvested in 2018 (USDA 2018). The reliance of humans on maize increases the impact of crop pests.

One such maize pest is the chrysomelid beetle, Diabrotica v. virgifera LeConte (western corn rootworm). This pest species is hypothesized to have originated from Mexico or 
Central America (Branson and Krysan 1981). It invaded large areas of North America and Canada (Gray et al. 2009) as well as of Europe (Miller et al. 2005; Szalai et al. 2011). It is a univoltine species with eggs that overwinter in the soil (Krysan and Miller 1986). After maize has germinated, the eggs soon hatch, and its three larval instars feed almost exclusively on maize roots (Moeser and Hibbard 2005). This often causes plant lodging (Levine and Oloumi-Sadeghi 1991). Efficient larval control appears difficult as the larval population hatches over a period of at least a month and is found feeding on maize roots in the soil for at least 2 months (Toepfer and Kuhlmann 2006). Corn rootworms cause approximately 1 billion dollars of crop losses and pest management costs in the USA annually (Krysan and Miller 1986; Rice 2004). In Europe, maize losses were estimated to account for 472 million euros, when no control measures would be implemented (Wesseler and Fall 2010).

The main pest management approaches include (1) synthetic insecticides such as granular or fluid soil insecticides as well as seed coatings against larvae, or foliar sprays against adults; (2) entomopathogenic nematodes against the larvae; (3) cultural control of the larvae through crop rotation; or (4) transgenic maize through expressing insecticidal proteins in the roots (Levine and Oloumi-Sadeghi 1991; van Rozen and Ester 2010).

Particularly soil applications of synthetic insecticides into the furrow at sowing have been reported to reduce larval damage to roots and to prevent plant lodging (Sutter et al. $1989,1990)$, such as for tefluthrin, chlorpyrifos ethyl, clothianidin, and $\lambda$-cyhalothrin (Blandino et al. 2016). However, soil as well as foliar insecticides occasionally fail in sufficiently reducing populations of this pest. As for adult control, pesticide inconsistency in efficacy has been often attributed to insecticide resistance. Such resistances are indeed known for $D$. v. virgifera adults, such as against some chlorinated hydrocarbons since the 1960s (Ball and Weekman 1962; Ciosi et al. 2009), or methyl-parathion and carbaryl since the mid-1990s (Meinke et al. 1998). Another problem is that $D$. v. virgifera beetles are mobile and can immigrate from untreated into treated fields (Levine and Oloumi-Sadeghi 1991; Gray et al. 1992). As for the larvae, less is known on their resistance to pesticides. However, adult resistance to pesticides is suggested to be inherited to the larvae and to reduce their susceptibility to certain pesticides (Wright et al. 2000). This was, for example, shown for larvae originating from adults in North America with resistance to methyl-parathion, terbufos, chlorpyrifos, carbofuran, and tefluthrin (Wright et al. 2000), and to bifenthrin (Pereira et al. 2015).

Nevertheless, even in areas where resistance has not yet been observed, soil pesticides have been reported to lead to inconsistent levels of root protection (Sutter et al. 1989; Furlan et al. 2006) and D. v. virgifera reduction (Gray et al.
1992; Boetel et al. 2003). As all larval instars of D. v. virgifera are susceptible to the pesticides, other factors may influence control efficacies. The chemical properties of insecticides (e.g. water solubility, evaporation) (Devare et al. 2004; Whiting et al. 2014), biodegradation levels through microbial activity (Chapman and Harris 1990), and the effect of environmental factors (soil properties, rainfall, temperature) on both may play roles in changing efficacies of treatments. Nevertheless, some soil pesticides such as chlorpyrifos, terbufos, or fonofos seem to well persist in the soil for up to 5 months being able to kill $D$. v. virgifera larvae and not being much influenced by rainfall and depletion. Other pesticides seem to be occasionally washed out or degrade as a result of rainfall, such as carbofuran or isofenphos (Sutter et al. 1989). In contrast, lack of soil moisture may generally lead to insufficient vertical and horizontal movement of an insecticide in the root zone and to less contact with the larvae (Sutter et al. 1991). Unfortunately, for some currently used insecticides, no such information is available from field conditions.

Any decrease or increase in efficacies of soil pesticides over the long period of 2 to 3 months of the larval population being in the soil should be also reflected in changed temporal emergence patterns of the adults from the soil. Female larvae seem to hatch from eggs on average at least 3 days later than the male larvae and need at least 2 days longer for their development to adults (Branson 1987). This may have implications on the efficacy of treatments. For example, Boetel et al. (2003) reported from a 3-year study that tefluthrin delayed the emergence of female $D$. barberi adults in at least two seasons and terbufos delayed the emergence of female $D$. v. virgifera adults in one season. Although results were not consistent in their studies, this may indicate that late female larvae may have been less reached by those pesticides in those years. Similarly, Sutter et al. (1991) reported from a 4-year study that ethoprop and chlorpyrifos delayed the $50 \%$ emergence of D. v. virgifera adults in one of four seasons, and carbofuran did so in two of four seasons. Otherwise, there is limited published information on temporal changes of soil pesticides in larval control and subsequent adult emergence patterns under field conditions, and if available reasons remain often unclear.

Due to the occasional failure and due to bans of some insecticides in maize, a biological control product had been developed based on the entomopathogenic nematode Heterorhabditis bacteriophora Poinar (Nematoda: Rhabditida) (Babendreier et al. 2006; Kergunteuil et al. 2016). It has recently reached the market in a number of European countries, such as Germany, Italy, Austria, or Hungary (Ehlers 2003; Toepfer et al. 2008). Nematodes can effectively kill all three larval instars of D. v. virgifera. Pilz et al. (2009) found in a 2-year field study that $H$. bacteriophora achieved, similar to tefluthrin, around $60 \%$ efficacy at reducing $D . v$. 
virgifera, while clothianidin seed coating achieved around $70 \%$. This suggests comparable efficacies of entomopathogenic nematodes to conventional insecticides. Unfortunately, also entomopathogenic nematodes seem variable in their efficacy at reducing $D$. v. virgifera and in preventing root damage when applied under field conditions (Toepfer et al. 2010a, c). In some cases, they may even entirely fail to control this pest (Rauch et al. 2017). Reasons behind inconsistencies and failures of nematodes under field conditions are still not fully understood. They likely include inappropriate handling of the living nematodes during storage, transport and mixing (Toepfer et al. 2010b), or suboptimal application, such as onto-soil sprays instead of into-soil applications of the moisture-requiring nematodes (Toepfer et al. 2010c). However, once successfully applied into the soil, nematodes seem well protected as the seed placement area is usually sufficiently moist. Moreover, nematodes can vertically move up and down in soil depending on moisture. Therefore, a positive effect of rainfall or the amount of water used for nematode application on the success of entomopathogenic nematodes is rarely found in the case of $D$. v. virgifera in maize fields (Toepfer et al. 2010a). Nematodes also seem to persist long enough in the soil to attack larvae and even propagate in them, an obvious advantage over pesticides. Thus, similar to soil pesticides, reasons behind inconsistency in efficacy results of nematodes under field conditions are little understood.

Therefore, we tried to better understand the occasionally suboptimal control efficacies of soil pesticides and entomopathogenic nematodes using existing data from a large number of field experiments (Ehlers et al. 2008; Toepfer et al. 2010a, c). Our hypotheses were that (a) soil insecticides may rather kill the early than late hatching larvae due to depletion or degradation of the active ingredients with time, and (b) entomopathogenic nematodes may increasingly reduce larvae with time due to propagation in the pest. Our analyses were based on the idea that such temporal changes in the efficacy of the applied control methods on the larvae should be also reflected in a change in temporal adult emergence patterns later in the cropping season (Sutter et al. 1991; Boetel et al. 2003). This could be reflected in shifts in time periods elapsed between emergence start and attaining linear adult emergence compared to untreated controls, in shifts in emergence peaks, or in changing emergence rates over time. We therefore applied such analyses to data from 12 different field-scale experiments from southern Hungary between 2010 and 2018 (Ehlers et al. 2008; Toepfer et al. 2010a, c).

Results may explain some of the reasons behind successes and failures of chemical and biological control methods. This may allow adaptations or further developments with the ultimate aim to provide growers with more effective and more diverse pest management tools.

\section{Methods}

\section{Field sites}

This study was carried out on 12 conventionally managed maize fields in southern Hungary between 2010 and 2018 (Table 1). All fields had been ploughed in autumn after the end of the previous cropping season and then tilled and harrowed in early to mid-April prior sowing maize. All sowing dates (Table 1) were within the southern Hungarian standard period for maize sowing, which is from mid-April to first week of May. Individual maize seeds were sowed every 16 to $18 \mathrm{~cm}$ in rows $75 \mathrm{~cm}$ apart, leading to $72-87,000$ plants per ha using a 4-row or 6-row planter. All seeds had been coated with standard fungicides.

\section{Target organism}

The target organism was Diabrotica virgifera ssp. virgifera LeConte (Coleoptera: Chrysomelidae). Study fields had hardly any natural population of D.v. virgifera because nonmaize crops had been planted the previous season or 2 years before (except fourth year maize in field $\mathrm{P}$, Table 1). Therefore, the life cycle of the maize-restricted $D$. v. virgifera larvae was disrupted. Instead, plants were artificially infested with $D$. v. virgifera eggs to simulate well-established, but homogenously distributed pest populations. Eggs were obtained from a laboratory culture of field-collected beetles in southern Hungary in August and September the previous year (for procedures, see Singh and Moore 1999). Artificial infestations are known to lead to similar larval development and adult emergence as natural populations (Fisher 1984). Diabrotica $v$. virgifera eggs were overwintered for 7 months at 6 to $8{ }^{\circ} \mathrm{C}$ in moist sand and 60 to $70 \%$ of eggs successfully overwintered. Diapause was broken during third or fourth week of April the following year by transferring eggs to 22 to $24{ }^{\circ} \mathrm{C}$.

Two sets of six or seven subsequent maize plants of each experimental plot were infested with viable and ready-tohatch eggs per plant when the plants were at the first to fourth leaf stage (for egg densities and dates, see Table 1). Eggs were applied in $0.15 \%$ aqueous agar using a standard pipette ( $5 \mathrm{ml}$, Eppendorf company, Hamburg, Germany) in two to four portions of eggs (in about 1 to $2 \mathrm{ml}$ water-agar each) into 100- to 140-mm-deep holes at a distance of 110 to $190 \mathrm{~mm}$ from both sides of the maize plant early May (Table 1).

A portion of eggs was transferred onto moist filter paper in Petri dishes and incubated at 20 to $25{ }^{\circ} \mathrm{C}$ in the laboratory to monitor time of first hatch as well as hatching rate of the larvae. In the laboratory, $D$. v. virgifera larvae started to hatch around 1 week after egg application date and hatching 


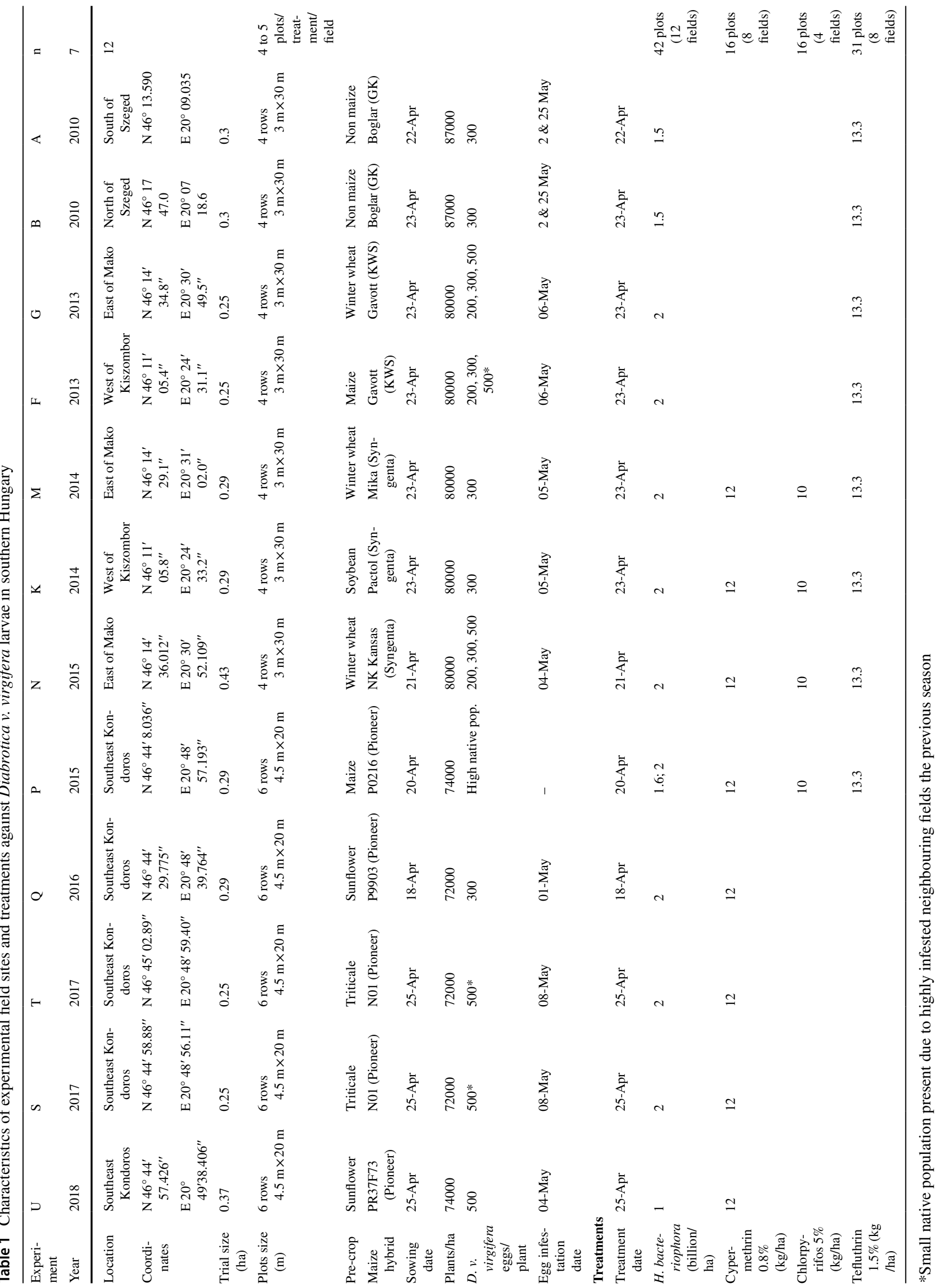


lasted until late May. An average hatching rate of $86 \pm 13 \%$ was determined. In the field, larvae were expected to emerge between the middle and end of May and second-instar larvae were expected early June (Toepfer and Kuhlmann 2006).

\section{Experimental design and treatments}

The temporal effect of a fluid formulation based on an entomopathogenic nematode as well as of granule formulations of three synthetic insecticides was studied on $D$. $v$. virgifera populations in 12 field-scale experiments (Table 1). All experiments were conducted according to the efficacy evaluation standards PP $1 / 212$ and PP $1 / 152$ of EPPO (Anonymous 1999, 2007). In each field, four to five plots of four to six maize rows ( 3 to $4.5 \mathrm{~m} \times 20$ to $30 \mathrm{~m}$ plots) per treatment and control were systematically arranged with changing orders between the different fields and years. No field location was used twice. For replicate numbers of each treatment, see Table 1.

All agents were applied at sowing into sowing row behind seed placement at about 80 to $110 \mathrm{~mm}$ depth as the maize was sown. All treatments were conducted over entire plots. Treatment and sowing dates were about one to 3 weeks prior egg hatch in the field.

In each plot, twice six to seven successive maize plants $(\approx 1.2 \mathrm{~m})$ were randomly chosen among the two middle rows of each of the four- to six-row wide plots for artificial infestation with ready-to-hatch $D$. v. virgifera eggs about a week later as described above, and for data assessments from June to August as described below.

\section{Heterorhabditis bacteriophora fluid}

In all 12 experimental fields (Table 1), mostly about 100,000 to 150,000 infective juveniles ( $i j)$ of a commercial hybrid of European and the USA strains of H. bacteriophora (Rhabditida: Heterorhabditidae; Dianem Wurzelbohrer ${ }^{\mathrm{TM}}$, e-nema company, Schwentinental, Germany) were applied per row meter. This was the equivalent of 1.5 to 2 billion nematodes per hectare. They were provided in a formulation of light inert powder (Formulation: Water soluble powder SP according to GIFAP code, $15 \%$ a.i. H. bacteriophora, $20 \%$ water, $65 \%$ inert ingredients mainly diatomaceous earth).

Approximately 1 to $2 \mathrm{~h}$ before application, the infective juveniles were diluted, together with the carrier material, in cool tap water to the required doses. Prior mixing, the living status of nematodes in the product batch had been determined under stereomicroscope, assuring an at least $70 \%$ survival rate. No adjuvants were used.

In fields A to N, a four-row self-made fluid applicator on a Pneumasem sowing machine (Nodet Gugis, Lacaille SA, France) was used applying the nematode fluid via gravity through tubes without nozzles behind the seed placement, and before the soil closing wheels (450 to 550 litres per ha). No seed pressing wheels were on the sowing machine.

In fields $\mathrm{P}$ to $\mathrm{U}$, a six-row self-made fluid applicator or a commercial fluid applicator (LIQ-Inject M1, Cult-tec GbR, Freiburg, Germany) were used on a Monosem NG sowing machine. Filters in the spraying system had been taken out. Tubes with core nozzles (Streamjet h1/4u -ss0010, TeeJet Spraying Systems Co., Wheaton, IL, USA) applied the nematode fluid after the seed placement, and before the soil closing wheels (200 litres per ha). No seed pressing wheels were on the sowing machine.

During application, subsamples of about $2 \mathrm{ml}$ nematode solution were taken from below the nozzles per treatment and field to determine the quality of nematodes arriving into the soil. Laboratory quality control bioassays with larvae of Tenebrio molitor L. (Coleoptera: Tenebrionidae) were used (Toepfer et al. 2008). If a mortality of 35 to $65 \%$ of $T$. molitor was found after 1 week, and 75 to $95 \%$ after 2 weeks, the applied nematodes were considered of sufficient level of virulence according to the nematode producer e-nema, which requires at least $50 \%$ mortality. This was the case for all presented experiments.

\section{Chlorpyrifos fine granules}

In four experimental fields (Table 1), about $0.75 \mathrm{~g}$ of fine granules ( 1 to $2 \mathrm{~mm}$ diameter, Formulation: Fine granule, FG of GIFAP code) of the soil insecticide chlorpyrifos, i.e. the organophosphate with the active substance O,O-diethyl O-3,5,6-trichloropyridin-2-yl phosphorothioate (Kentaur ${ }^{\mathrm{TM}}$ 5 G, 5\% Chlorpyrifos, Cheminova, Budapest, Hungary), were applied per row meter. This was the equivalent of the recommended dose of $10 \mathrm{~kg}$ granules per hectare. They were applied by a seeder-mounted fine granule applicator (Galdept-10 of Galenika Fitofarmacija, Srem Karlovci, Serbia; or MicroSem of Certis, UK), into seeding rows at about 80 to $110 \mathrm{~mm}$ depth into the soil just after seed placement.

\section{Cypermethrin micro-granules}

In eight experimental fields (Table 1), about $0.9 \mathrm{~g}$ of fine granules (0.8 to $1 \mathrm{~mm}$ diameter, Formulation: Microgranule, MG of GIFAP code) of the soil insecticide cypermethrin, i.e. the pyrethroid with the active substance [Cyano-(3-phenoxyphenyl)methyl]3-(2,2-dichloroethenyl)2,2-dimethylcyclopropane-1-carboxylate (Belem ${ }^{\mathrm{TM}} 0.8 \mathrm{MG}$, 0.8\% Cypermethrin, Spiess-Urania, Hamburg, Germany), were applied per row meter. This was the equivalent of $12 \mathrm{~kg}$ granules per hectare. However, due to its too fine granule size, the product had been diluted by $1 / 2$ using river sand of similar particle size and then applied by a seeder-mounted micro-granule applicator and applied as described above. 


\section{Tefluthrin fine granules}

In eight experimental fields (Table 1 ), $1 \mathrm{~g}$ of fine granules ( 1 to $2 \mathrm{~mm}$ diameter, Formulation: Fine granule, FG of GIFAP code) of the soil insecticide tefluthrin, i.e. the pyrethroid with the active substance 2,3,5,6-Tetrafluoro-4methylbenzyl(Z)-(1RS,3RS)-3-(2-chloro- 3,3,3-trifluoro1-propenyl-2,2-dimethylcyclopropanecarboxylate (Force ${ }^{\mathrm{TM}}$ $1.5 \mathrm{G}$, Syngenta, Budapest, Hungary), were applied per row meter. This was the equivalent of $13.3 \mathrm{~kg}$ per ha. They were applied by micro-granule applicators as described above.

\section{Untreated control}

Untreated D. v. virgifera egg-infested plots served as negative controls.

\section{Assessment of $D . v$. virgifera dynamics and reduction}

For each treatment and control, four to five sets of six to seven infested consecutive maize plants were cut to a height of about $100 \mathrm{~cm}$ and covered with gauze cages (inner size, $125 \mathrm{~cm} \times 40 \mathrm{~cm} \times 150 \mathrm{~cm}$ high). They were placed midJune, i.e. prior the predicted start of adult emergence (Toepfer and Kuhlmann 2006). To assess the temporal emergence patterns of $D$. v. virgifera adults, we counted the emerged beetles on a weekly basis following the procedures outlined in the EPPO standards (Anonymous 1999, 2007; Toepfer et al. 2008). Counted beetles were sexed according to antenna length (Gloyna, K. 2008 pers. comm.; Hammack and French 2007) and removed from the cages at each check. Adult emergence data were standardised to 100 eggs per plant per week (except for field $\mathrm{P}$ that hosted a native pest population). The weekly cumulative emergence was calculated per time step for all experiments. The efficacy of each treatment was calculated as the D. v. virgifera emergence relative to the control (corrected efficacy $\%=100 \times$ (beetles in control plots - beetles in treated plots)/maximum (beetles in control or treated plots). Root damage changes over weekly time steps were not assessed as roots would have been destroyed and therefore interrupted adult emergence.

\section{Data analyses}

Temporal dynamics of pooled sex, male and female adult emergence as well as their cumulative emergence were plotted over weeks using loess smoothed (local polynomial regression) lines (Figs. 1, 2, 3, 5).

The cumulative adult emergence curves (= local polynomial regression lines) were used to estimate the date of start and end of adult emergence (Table 2). Differences between male and female emergence start, their 25, 50, and $75 \%$ emergence, and their peak emergence were analysed for each treatment and controls using paired t tests (Table 3). Differences in male and female cumulative emergence patterns (time shift and steepness) were analysed by comparing their regression curves using GLMs (Fig. 3).

Linear models were used to identify and compare control effects of treatments as well as to investigate the influence of treatments, sex, and their interaction on efficacies with additionally performed basic diagnostic plots for assumption of residual normality and homoscedasticity, as well as plots of Cook's distance for detecting influential data points (Faraway 2004).

To assess the temporal effects of treatments on the reduction of D. v. virgifera, we assumed that temporal shifts in adult emergence patterns reflect potential shifts in larval control by the treatments. The cumulative emergence of the adults in cages of each treatment and experiment was standardised and plotted as a percentage of the corresponding total emergence (Figs. 1, 5). This is (a) to standardise the different absolute emergence levels between treatments and (b) to standardise different $D$. v. virgifera densities across experiments. To identify temporal effects of treatments on D. v. virgifera, the deviances of the following quasi-binominal GLMs with logit link functions were compared using an F-test: one model with the explanatory variables time (days after emergence start), treatment (pairs of a particular treatment and control), and their interaction versus the second model with the single explanatory variable time. Those steps were performed separately for pooled sex, male, and female data, each treatment totalling in 12 comparisons of model deviances. Where a temporal effect was identified, the explanatory variables were tested separately using $t$ tests to clarify whether the treatment (shift in time) or the interaction of treatment $x$ time (steepness of the curve) or both influenced the temporal pattern of $D$. v. virgifera adult emergence. $P$ values were corrected for false discovery rates using Benjamini and Hochberg method (Benjamini and Hochberg 1995).

$\mathrm{R}$ statistical software was used for all analyses (version: 3.5.2., R Development Core Team 2018)).

\section{Results}

\section{Temporal population dynamics}

Per maize plant, $1.5 \pm 1.8$ (SD) Diabrotica v. virgifera adults emerged on average per 100 infested eggs; that is, $0.8 \pm 1$ males and $0.7 \pm 0.9$ females ( $n=11$ fields) which is around some of the economic thresholds used in the USA (see 1.6 adults per plant, Godfrey and Turpin 1983). Diabrotica v. virgifera adults emerged in southern Hungary during a period of about 6 weeks between mid-June to early July and end July to mid-August, i.e. during $45 \pm 5$ days (min.: 
Early treatment effect
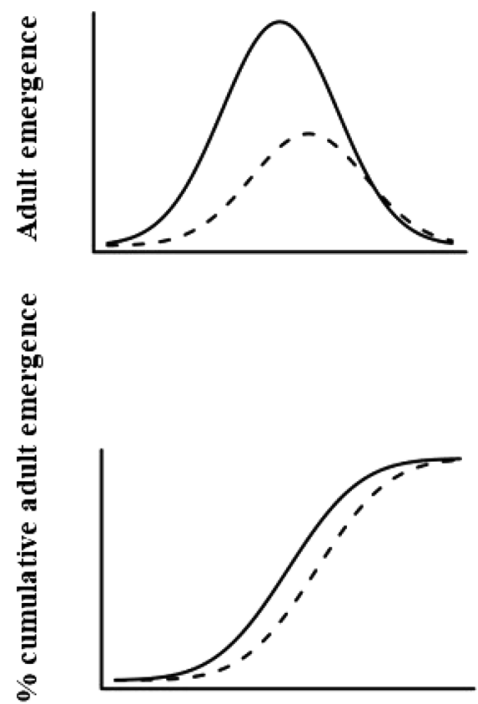

Continuous treatment effect
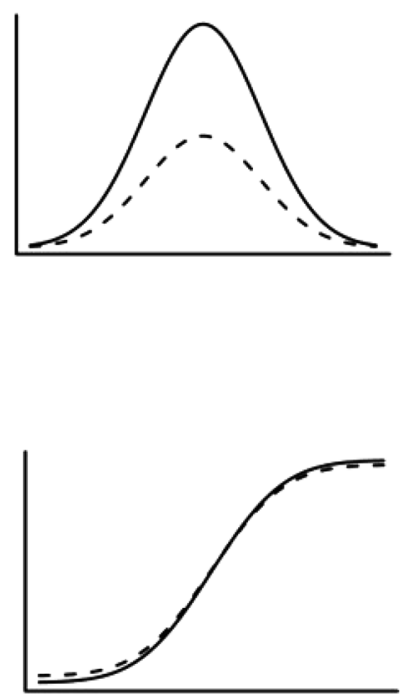

Late treatment effect

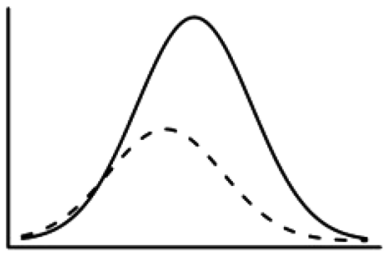

- - - Treated

Control

Days after adult emergence start

Fig. 1 Hypothetical temporal effects of treatments on Diabrotica v. virgifera reflected in the emergence patterns of adults over time and standardised as per cent cumulative emergence of the corresponding total emergence in a season. Smoothed trend lines plotted

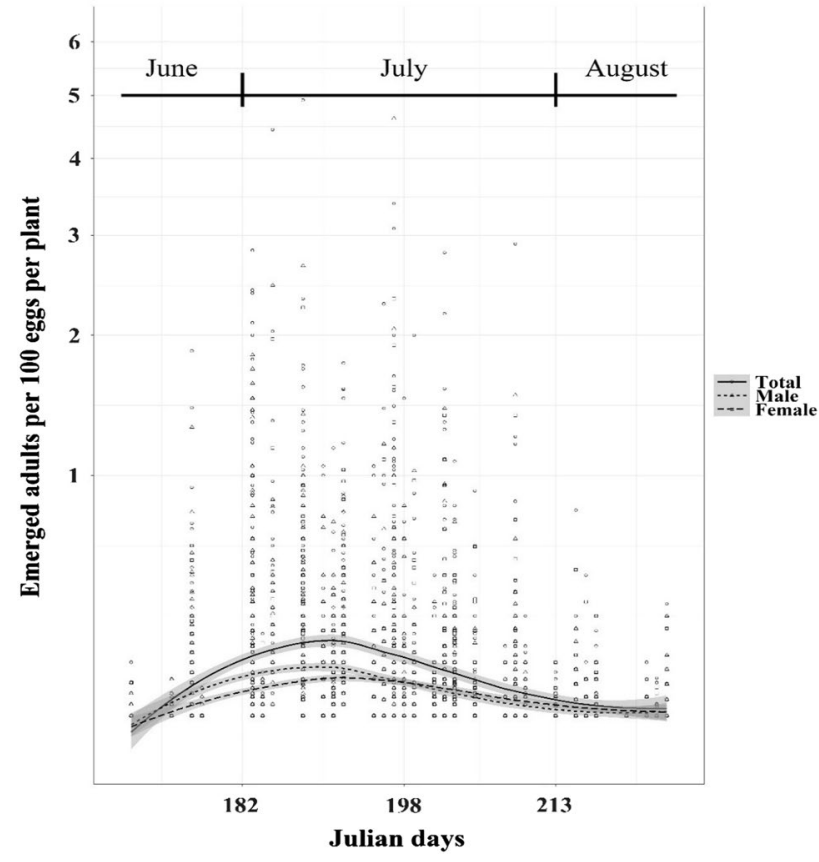

Fig. 2 Temporal dynamics of adult emergence of Diabrotica virgifera virgifera standardised per 100 eggs per plant in 11 artificially infested maize fields in Hungary between 2010 and 2018 (data from untreated control plots, smoothed trend lines)

36 days; max.: 53 days) (Fig. 2, Table 2). The start of emergence largely varied between years with an early start around 14 June in 2018 and a late start around 7 July in 2010. Half of the adults usually emerged until 10 July \pm 8 days (192 Julian days), and this is about 16 days after emergence start. During the same date, the peak emergence of adults was ongoing. Adult stopped emerging around 9 August \pm 7 days (Table 2).

Male and female beetles emerged over a period of $45 \pm 5$ and $43 \pm 6$ days, respectively (Table 2, Fig. 2) with comparable emergence curves (GLM: time $\times$ sex interaction: comparable curve steepness, $p=0.64$ ). Male populations emerged earlier than female populations (time shift in GLM regression curves, $p<0.001$, Table 1, Fig. 3). The first record of males in the emergence gauze cages was about 1 day before the female first record. Half of the male population had emerged already $5 \pm 8$ days before the female population (50\% at 7 July \pm 9 days vs. 12 July \pm 8 days; paired $t$ test: $p=0.02, \mathrm{CI}_{95 \%}=1,9.5$ days, Table 2, Fig. 2, 3). Males reached their peak emergence around $8 \pm 11$ days earlier than females ( 8 July \pm 9 days versus 16 July \pm 7 days; $p=0.03$, $\mathrm{CI}_{95 \%}=0.69,14.47$, Table 2, Fig. 2, 3).

\section{Efficacy at reducing $D$. v. virgifera}

All tested products regardless of chemical or biological were able to reduce male and/or female Diabrotica v. virgifera. Variability in efficacy appeared high (see SEMs in Fig. 4). All treatments occasionally failed to sufficiently reduce pest populations, i.e. no statistical difference was detected between adult numbers in treated and untreated plots. Chlorpyrifos failed in one of four experiments (25\%), 
Fig. 3 Protandry in Diabrotica virgifera virgifera adult emergence presented as cumulative emergence over time in 12 maize fields in southern Hungary between 2010 and 2018 (data from untreated control plots, smoothed trend lines)

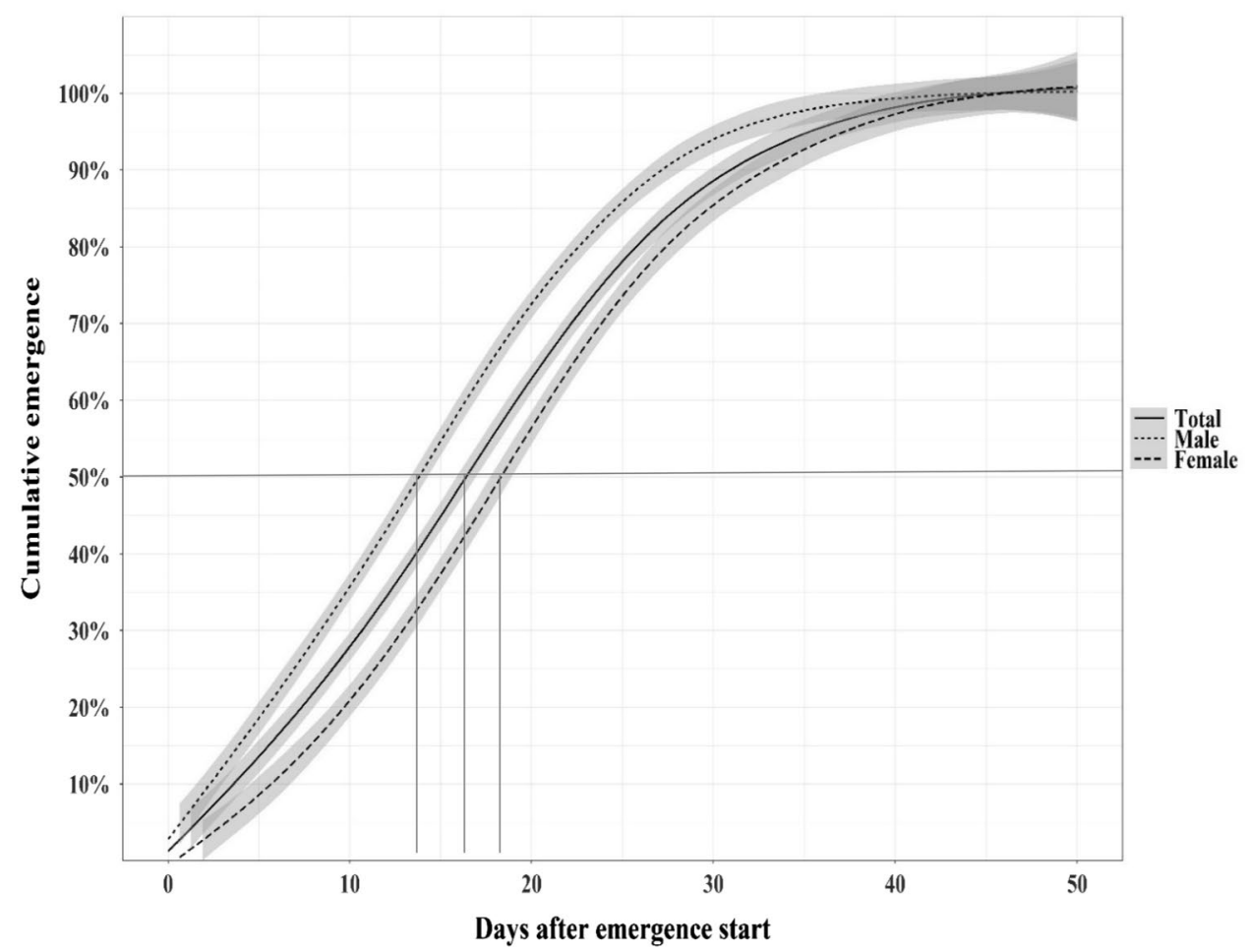

cypermethrin and tefluthrin in two of eight (25\%), and $H$. bacteriophora in three of 12 experiments (25\%).

Considering both sexes together, cypermethrin, tefluthrin, and $H$. bacteriophora reduced $D$. $v$. virgifera with comparable efficacies (Fig. 4, $p=0.94$ of GLM for explanatory variable treatment). In detail, cypermethrin reduced $48 \pm 33$ (SD) of D. v. virgifera on average across fields and years (GLM, fdr-corrected $p=0.004$ ); tefluthrin reduced $39 \pm 43 \%$ $(p=0.002)$, and $H$. bacteriophora reduced $34 \pm 37 \%$ $(p=0.002)$. However, such control efficacies were statistically not detected for chlorpyrifos $(p=0.09)$.

When considering the reduction of males and females separately, a similar picture was found for the male control efficacies as for the pooled-sex efficacy described above (GLM, explanatory variable sex, $p=0.83$; treatment $\mathrm{x}$ sex, $p=0.82)$. Most treatments reduced males, i.e. cypermethrin (fdr-corrected $p=0.005)$, tefluthrin $(p=0.005), H$. bacteriophora $(p=0.004)$, but chlorpyrifos did not $(p=0.2)$. As for females, all treatments including chlorpyrifos $(p=0.02)$ were able to reduce Diabrotica $v$. virgifera (cypermethrin: $p=0.02$, tefluthrin: $p<0.001, H$. bacteriophora: $p<0.001)$.

\section{Temporal effects of treatments}

All treatments regardless of chemical or biological had no major efficacy changes in reducing $D$. $v$. virgifera over time (Fig. 5, Table 3). The time needed to reach 25, 50, peak, or $75 \%$ adult emergence did not differ between treatments and the untreated control (Table 3 ).
In detail, Heterorhabditis bacteriophora and cypermethrin continuously reduced $D$. v. virgifera larvae over time, regardless of insect sex (Fig. 5). This is because there was no temporal effect of those treatments found on the adults' standardised cumulative emergence curve compared to the standardised emergence curve in the untreated control. In other words, no difference was found between logistic GLMs with factor treatment (levels of a certain treatment and control) x time versus GLMs with time only (Fig. 5).

Chlorpyrifos slightly better controlled early than late female larvae (Fig. 5). This is because there was no temporal effect of chlorpyrifos detected on the standardised male or pooled-sex cumulative emergence curve compared to the control curve, but a slight temporal effect on the female curve (difference between logistic GLMs with factor treatment $\times$ time versus GLMs with time only, $p=0.03$, Fig. 5). This was reflected in a time shift (delay) in the adult female emergence curve according to the analyses of deviance of the emergence curve (logistic GLM treatment $\times$ time vs. emergence, $p=0.03$ ), but not due to a change in curve steepness $(p=0.11)$ (see curves in Fig. 5).

Tefluthrin continuously reduced male $D$. v. virgifera larvae over time, but slightly improved efficacy later on. This is reflected in a slightly better control of late than early female larvae. In other words, there was no temporal effect of tefluthrin detected on the standardised male adult emergence curve compared to the untreated control curve, but on the female and pooled-sex curves. This is reflected in both a time shift (earlier) in the emergence pattern and in a change 
Table 2 Temporal emergence patterns of adult Diabrotica virgifera virgifera in southern Hungary between 2010 and 2018 ( $n=4$ to 5 adult emergence gauze cages over 6 to 7 plants each, placed onto 4 to 5 untreated control plots per each of 12 maize fields)

\begin{tabular}{|c|c|c|c|c|c|c|c|c|}
\hline \multirow[b]{2}{*}{ Year } & \multirow[b]{2}{*}{ Experiment } & \multirow[b]{2}{*}{ Estimated start $^{+}$} & \multirow[b]{2}{*}{$\begin{array}{l}\text { First recorded } \\
\text { adults }\end{array}$} & \multicolumn{2}{|l|}{ Adult emergence } & \multirow[b]{2}{*}{$\begin{array}{l}\text { Last recorded } \\
\text { adults }\end{array}$} & \multirow[b]{2}{*}{ Estimated end ${ }^{+}$} & \multirow[b]{2}{*}{ 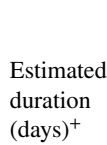 } \\
\hline & & & & $50 \%$ emergence & Peak emergence & & & \\
\hline \multicolumn{9}{|c|}{ Pooled sexes } \\
\hline 2018 & $\mathrm{U}$ & 14/06/2018* & 20/06/2018* & 03/07/2018 & 20/07/2018 & 20/07/2018* & 20/07/2018 & 36 \\
\hline 2017 & S & 20/06/2017 & $26 / 06 / 2017$ & 04/07/2017 & 09/07/2017 & $11 / 08 / 2017$ & $11 / 08 / 2017$ & 50 \\
\hline 2017 & $\mathrm{~T}$ & 20/06/2017 & $26 / 06 / 2017$ & 02/07/2017* & 04/07/2017 & 01/08/2017 & $11 / 08 / 2017 * * *$ & 50 \\
\hline 2016 & $\mathrm{Q}$ & 06/07/2016 & 02/07/2016 & 23/07/2016** & $15 / 07 / 2016$ & 09/08/2016 & $12 / 08 / 2016$ & 45 \\
\hline 2015 & $\mathrm{~N}$ & $24 / 06 / 2015$ & $24 / 06 / 2015$ & 06/07/2015 & 07/07/2015 & 05/08/2015 & 05/08/2015 & 42 \\
\hline 2015 & $\mathrm{P}^{++}$ & $25 / 06 / 2015$ & $25 / 06 / 2015$ & $12 / 07 / 2015$ & $16 / 07 / 2015$ & $10 / 08 / 2015$ & $10 / 08 / 2015$ & 46 \\
\hline 2014 & M & $19 / 06 / 2014$ & 02/07/2014 & 09/07/2014 & 02/07/2014* & 05/08/2014 & 07/08/2014 & 49 \\
\hline 2014 & $\mathrm{~K}$ & $19 / 06 / 2014$ & 02/07/2014 & 06/07/2014 & 02/07/2014* & 05/08/2014 & $11 / 08 / 2014$ & 53 \\
\hline 2013 & G & $25 / 06 / 2013$ & $27 / 06 / 2013$ & 03/07/2013 & 08/07/2013 & 01/08/2013 & 08/08/2013*** & 45 \\
\hline 2013 & $\mathrm{~F}$ & $27 / 06 / 2013$ & 27/06/2013 & $17 / 07 / 2013$ & $17 / 07 / 2013$ & 01/08/2013 & 08/08/2013*** & 50 \\
\hline 2010 & A & 07/07/2010 & $07 / 07 / 2010 * *$ & $22 / 07 / 2010$ & $15 / 07 / 2010$ & $12 / 08 / 2010 * *$ & $18 / 08 / 2010$ & 43 \\
\hline 2010 & B & $07 / 07 / 2010 * *$ & $07 / 07 / 2010 * *$ & $19 / 07 / 2010$ & $22 / 07 / 2010 * *$ & $12 / 08 / 2010 * *$ & $18 / 08 / 2010$ & 42 \\
\hline Mean & & 24 June & 28 June & 10 July & 11 July & 6 August & 8 August & \\
\hline Mean & $\pm \mathrm{SD}$ & $176 \pm 7$ & $180 \pm 5$ & $192 \pm 8$ & $193 \pm 7$ & $219 \pm 6$ & $221 \pm 7$ & $45 \pm 5$ \\
\hline \multicolumn{9}{|c|}{ Males } \\
\hline 2018 & $\mathrm{U}$ & $14 / 06 / 2018^{*}$ & 20/06/2018* & $21 / 06 / 2018^{*}$ & $20 / 06 / 2018 * *$ & 20/07/2018* & $20 / 07 / 2018$ & 36 \\
\hline 2017 & s & $19 / 06 / 2017$ & 26/06/2017 & 02/07/2017 & 09/07/2017 & $11 / 08 / 2017$ & $11 / 08 / 2017$ & 50 \\
\hline 2017 & $\mathrm{~T}$ & 20/06/2017 & $26 / 06 / 2017$ & 03/07/2017 & 04/07/2017 & 01/08/2017 & $11 / 08 / 2017 * * *$ & 50 \\
\hline 2016 & $\mathrm{Q}$ & 05/07/2016 & $02 / 07 / 2016$ & $18 / 07 / 2016$ & $15 / 07 / 2016$ & 09/08/2016 & $15 / 08 / 2016$ & 48 \\
\hline 2015 & $\mathrm{~N}$ & $24 / 06 / 2015$ & $24 / 06 / 2015$ & 05/07/2015 & 07/07/2015 & 05/08/2015 & 05/08/2015 & 42 \\
\hline 2015 & $\mathrm{P}^{++}$ & $25 / 06 / 2015$ & $25 / 06 / 2015$ & $12 / 07 / 2015$ & $16 / 07 / 2015$ & $10 / 08 / 2015$ & $10 / 08 / 2015$ & 46 \\
\hline 2014 & $\mathrm{M}$ & $19 / 06 / 2014$ & 02/07/2014 & 05/07/2014 & 02/07/2014* & 05/08/2014 & 05/08/2014 & 47 \\
\hline 2014 & $\mathrm{~K}$ & $19 / 06 / 2014$ & 02/07/2014 & 05/07/2014 & 02/07/2014* & 05/08/2014 & 08/08/2014 & 50 \\
\hline 2013 & G & $25 / 06 / 2013$ & $27 / 06 / 2013$ & 03/07/2013 & 08/07/2013 & $01 / 08 / 2013$ & $08 / 08 / 2013^{* * *}$ & 45 \\
\hline 2013 & $\mathrm{~F}$ & $27 / 06 / 2013$ & $27 / 06 / 2013$ & $15 / 07 / 2013$ & $17 / 07 / 2013$ & $01 / 08 / 2013$ & 08/08/2013*** & 50 \\
\hline 2010 & A & 07/07/2010 & 07/07/2010* & $22 / 07 / 2010 * *$ & $16 / 07 / 2010$ & $12 / 08 / 2010 * *$ & 06/07/2010 & 42 \\
\hline 2010 & в & $07 / 07 / 2010^{* *}$ & $07 / 07 / 2010 *$ & $17 / 07 / 2010$ & $20 / 07 / 2010 * *$ & $12 / 08 / 2010 * *$ & $18 / 08 / 2010$ & 42 \\
\hline Mean & & 24 June & 28 June & 7 July & 8 July & 6 August & 8 August & \\
\hline Mean & $\pm \mathrm{SD}$ & $176 \pm 7$ & $180 \pm 5$ & $189 \pm 9$ & $190 \pm 9$ & $219 \pm 6$ & $221 \pm 8$ & $45 \pm 5$ \\
\hline \multicolumn{9}{|c|}{ Females } \\
\hline 2018 & $\mathrm{U}$ & $20 / 06 / 2018 *$ & 20/06/2018* & 07/07/2018 & $20 / 07 / 2018$ & $20 / 07 / 2018 *$ & $20 / 07 / 2018$ & 36 \\
\hline 2017 & S & $23 / 06 / 2017$ & 26/06/2017 & 05/07/2017 & $11 / 07 / 2017$ & $11 / 08 / 2017$ & $11 / 08 / 2017$ & 50 \\
\hline 2017 & $\mathrm{~T}$ & $22 / 06 / 2017$ & $26 / 06 / 2017$ & 03/07/2017 * & 05/07/2017* & $01 / 08 / 2017$ & $11 / 08 / 2017$ & 50 \\
\hline 2016 & $\mathrm{Q}$ & 06/07/2016 & 02/07/2016 & $26 / 07 / 2016 * *$ & 23/07/2016 & 09/08/2016 & $11 / 08 / 2016$ & 44 \\
\hline 2015 & $\mathrm{~N}$ & $24 / 06 / 2015$ & $02 / 07 / 2015$ & 08/07/2015 & $10 / 07 / 2015$ & 05/08/2015 & 05/08/2015 & 42 \\
\hline 2015 & $\mathrm{P}^{++}$ & $25 / 06 / 2015$ & $25 / 06 / 2015$ & $13 / 07 / 2015$ & $16 / 07 / 2015$ & $10 / 08 / 2015$ & $10 / 08 / 2015$ & 46 \\
\hline 2014 & $\mathrm{M}$ & $19 / 06 / 2014$ & 02/07/2014 & $18 / 07 / 2014$ & $28 / 07 / 2014 * *$ & 05/08/2014 & 06/08/2014 & 48 \\
\hline 2014 & $\mathrm{~K}$ & $19 / 06 / 2014$ & 02/07/2014 & 09/07/2014 & 20/07/2014 & 05/08/2014 & 06/08/2014 & 48 \\
\hline 2013 & G & $26 / 06 / 2013$ & 02/07/2013 & 04/07/2013 & 09/07/2013 & 01/08/2013 & 08/08/2013*** & 45 \\
\hline 2013 & $\mathrm{~F}$ & $25 / 06 / 2013$ & $02 / 07 / 2013$ & $17 / 07 / 2013$ & $17 / 07 / 2013$ & $01 / 08 / 2013$ & 08/08/2013*** & 50 \\
\hline 2010 & A & 04/07/2010 & $07 / 07 / 2010 * *$ & $21 / 07 / 2010$ & $16 / 07 / 2010$ & $12 / 08 / 2010 * *$ & $12 / 08 / 2010$ & 37 \\
\hline 2010 & В & $07 / 07 / 2010^{* * *}$ & $07 / 07 / 2010 * *$ & $21 / 07 / 2010$ & $22 / 07 / 2010$ & $12 / 08 / 2010^{* *}$ & $17 / 08 / 2010$ & 41 \\
\hline \multicolumn{2}{|c|}{ Mean (date) } & 25 June & 29 June & 12 July & 16 July & 6 August & 7 August & \\
\hline \multicolumn{2}{|c|}{ Mean $($ Julian days $) \pm S D$} & $177 \pm 6$ & $181 \pm 5$ & $194 \pm 8$ & $198 \pm 7$ & $219 \pm 6$ & $220 \pm 7$ & $43 \pm 6$ \\
\hline
\end{tabular}

+Local polynomial regression lines of cumulative emergence used to estimate the earliest/latest date of emergence in cases where beetles had been found in the emergence cages at the first or last check

++ Field $\mathrm{P}$ was the only field with heavy natural $D$. v.virgifera population, but their emergence did not deviate from average emergence patterns across experiments

*Earliest among experiments

**Latest among experiments

***Not estimated end-data, but real data, i.e. no beetles were found any more in emergence cages 
Table 3 Temporal difference of cumulative Diabrotica v. virgifera adult emergence between treatments and the untreated control (days \pm SD) in 4 to 12 maize fields in Hungary between 2010 and 2018. Days reaching a certain percentage of cumulative emergence in a treatment subtracted from the days of the corresponding emergence in the untreated control with $p$ values according paired $t$ test ( $p$ values in brackets are fdr-corrected using the Benjamini and Hochberg method)

\begin{tabular}{|c|c|c|c|c|c|c|c|c|}
\hline \multirow[b]{3}{*}{ Treatments } & \multicolumn{8}{|c|}{ Cumulative adult emergence } \\
\hline & \multicolumn{2}{|l|}{$25 \%$} & \multicolumn{2}{|l|}{$50 \%$} & \multicolumn{2}{|l|}{ Peak } & \multicolumn{2}{|l|}{$75 \%$} \\
\hline & $\begin{array}{l}\text { Day difference } \\
\text { to control }\end{array}$ & $p$ values & $\begin{array}{l}\text { Day difference } \\
\text { to control }\end{array}$ & $p$ values & $\begin{array}{l}\text { Day difference } \\
\text { to control }\end{array}$ & $p$ values & $\begin{array}{l}\text { Day difference } \\
\text { to control }\end{array}$ & $p$ values \\
\hline \multicolumn{9}{|l|}{ Pooled sexes } \\
\hline Chlorpyrifos & $1.8 \pm 2.2$ & $0.21(0.79)$ & $0 \pm 2.5$ & $0.12(0.79)$ & $1.5 \pm 5.1$ & $0.09(0.79)$ & $-0.8 \pm 4.2$ & $0.75(0.87)$ \\
\hline Cypermethrin & $0.1 \pm 4.9$ & $0.95(0.98)$ & $-1.4 \pm 1.9$ & $0.49(0.79)$ & $2 \pm 6.8$ & $0.14(0.79)$ & $-1.8 \pm 3.7$ & $0.22(0.79)$ \\
\hline H. bacteriophora & $-0.4 \pm 3.4$ & $0.55(0.79)$ & $-0.5 \pm 2.8$ & $0.54(0.79)$ & $-0.2 \pm 6.4$ & $0.78(0.87)$ & $-0.6 \pm 2.5$ & $0.42(0.79)$ \\
\hline Tefluthrin & $0.5 \pm 3.5$ & $0.7(0.79)$ & $-0.5 \pm 4.3$ & $0.75(0.87)$ & $4.6 \pm 8.8$ & $0.15(0.79)$ & $-1.8 \pm 4.5$ & $0.23(0.79)$ \\
\hline \multicolumn{9}{|l|}{ Male } \\
\hline Chlorpyrifos & $0.5 \pm 1.3$ & $0.5(0.79)$ & $-2.2 \pm 2.8$ & $0.53(0.79)$ & $0.1 \pm 4.6$ & $0.4(0.79)$ & $1.8 \pm 2.8$ & $0.31(0.79)$ \\
\hline Cypermethrin & $0.6 \pm 3$ & $0.58(0.79)$ & $-1.9 \pm 3.8$ & $0.48(0.79)$ & $-3.2 \pm 7$ & $1(1)$ & $1.4 \pm 5.8$ & $0.53(0.79)$ \\
\hline H. bacteriophora & $-0.1 \pm 2.9$ & $0.09(0.79)$ & $0.5 \pm 3.4$ & $0.36(0.79)$ & $-0.4 \pm 7.2$ & $0.36(0.79)$ & $0.4 \pm 3.2$ & $0.48(0.79)$ \\
\hline Tefluthrin & $-0.8 \pm 3.3$ & $0.54(0.79)$ & $0.5 \pm 4.1$ & $0.24(0.79)$ & $0.3 \pm 4.4$ & $0.29(0.79)$ & $-3.8 \pm 5.1$ & $0.84(0.91)$ \\
\hline \multicolumn{9}{|l|}{ Female } \\
\hline Chlorpyrifos & $1.8 \pm 3.6$ & $0.5(0.79)$ & $-0.2 \pm 2.6$ & $0.5(0.79)$ & $-4.3 \pm 13.3$ & $0.42(0.79)$ & $-0.5 \pm 3.3$ & $0.78(0.87)$ \\
\hline Cypermethrin & $0.8 \pm 1.9$ & $0.30(0.79)$ & $-2 \pm 3.2$ & $0.59(0.79)$ & $-0.6 \pm 7$ & $0.73(0.87)$ & $-1.3 \pm 2.4$ & $0.2(0.79)$ \\
\hline H. bacteriophora & $0 \pm 3.1$ & $1(1)$ & $0 \pm 2.2$ & $0.89(0.95)$ & $-2 \pm 4.8$ & $0.29(0.79)$ & $0.7 \pm 3.5$ & $0.51(0.79)$ \\
\hline Tefluthrin & $0.8 \pm 3.8$ & $0.6(0.79)$ & $-0.7 \pm 4$ & $0.42(0.79)$ & $0 \pm 4.6$ & $0.77(0.87)$ & $-2 \pm 4.5$ & $0.25(0.79)$ \\
\hline
\end{tabular}

in steepness of the curve (logistic GLM treatment $\times$ time vs. emergence, pooled-sex shift $p=0.033$; steepness $p=0.006$; females $p=0.025 ; p<0.001$ ).

When adjusting the $p$ values of the pairwise curve comparisons between treatment and control adult emergence for false discovery, no temporal treatment effects were found for Heterorhabditis bacteriophora, cypermethrin, and chlorpyrifos (see $p$ values in brackets in Fig. 5). The only remaining effect was tefluthrin's increasing efficacy over time in controlling females (fdr-corrected $p=0.002$ ).

\section{Discussion}

Larvae of the root-feeding maize pest $D$. v. virgifera are difficult to control due to their relatively long egg-hatching period (Toepfer and Kuhlmann 2006), and an at least 2-month long period of a population of its three larval instars feeding on and inside the roots (Levine and Oloumi-Sadeghi 1991). However, our multiple-location, multiple-year field study showed that common soil insecticides such as the pyrethroids tefluthrin and cypermethrin or the organophosphate chlorpyrifos can, with few exceptions, successfully reduce $D$. v. virgifera larvae over a relatively long period. The same was true for the applied entomopathogenic nematode. Nematodes are known to be able to propagate in $D$. v. virgifera larvae and can subsequently attack new larvae and therefore persist in field soils for several months (Pilz et al. 2014).

To better understand whether pesticides' control efficacies may decrease over time, and nematode efficacies may increase due to propagation, we investigated possible changes in the efficacies of such treatments during their control of the pest larvae in the soil.

First, we time-plotted the adult emergence from the untreated plots of field-scale experiments from different locations and years to get a general picture about the adult emergence dynamics under field conditions. The average adult emergence started between mid to end of June in southern Hungary (Figs. 2, 3, Table 1), which is comparable to previous studies from Hungary (Toepfer and Kuhlmann 2006) and Croatia (Bazok 2001). In the US Corn Belt, adult emergence may begin in late June to early July with peak emergence often occurring during July (Darnell et al. 2000; Nowatzki et al. 2002; Meinke et al. 2009). In our study in Hungary, adults emerged during around 45 days across locations and years, which is comparable to the USA. In Iowa, duration of emergence from 78 continuous maize fields over a 6-year study averaged 33 days for males and 51 days for females (Meinke et al. 2009). Our data also confirmed that male $D$. v. virgifera adults emerge earlier than the females and reach their 50\% emergence around five days before the 


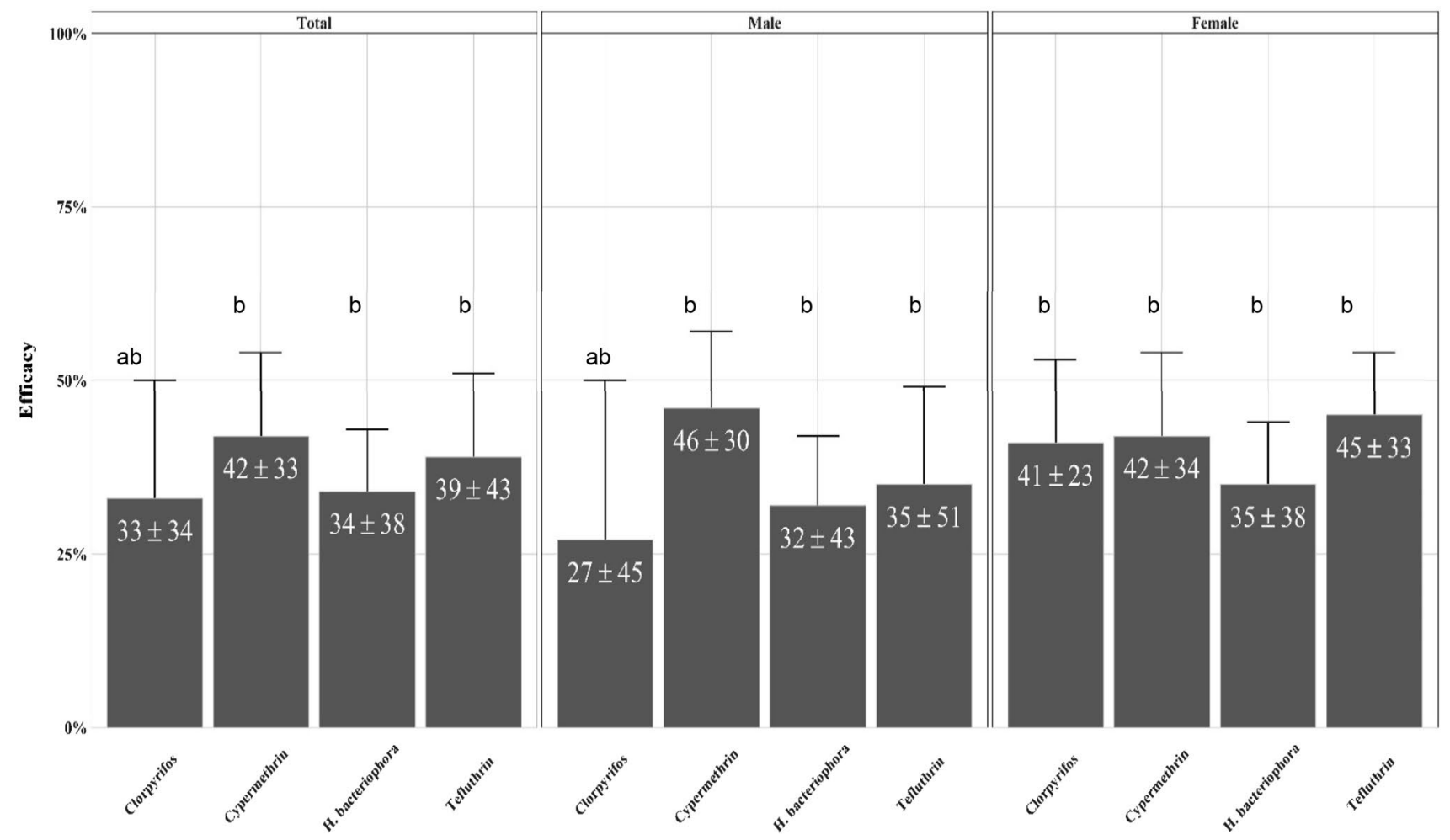

Fig. 4 Efficacy of chemical and biological treatments at reducing Diabrotica v. virgifera in 12 maize fields in Hungary between 2010 and 2018. 4 to 5 plots with 6 to 7 assessed plants per treatment per field. Efficacy is the adult emergence in a treatment compared to

females (Fig. 3), as it has been already observed in many other studies (Ruppel et al. 1978; Branson 1987; Nowatzki et al. 2002; Meinke et al. 2009). The apparently low adult emergence rate of less than $5 \%$ of the initial egg infestation is normal for this species due to high natural mortality on its larval stages (Toepfer et al. 2006).

On average across the diverse field and year situations of our study, all treatments, regardless of chemical or biological, comparably reduced around 33 to $46 \%$ of $D$. v. virgifera adult emergence (overall mean 38\%). Those efficacies seem lower than those reported from several single field trials (Rozen and Ester 2010; Pilz et al. 2014), but correspond well to the ranges of pesticide efficacies found in larger field studies (Sutter et al. 1991; Gray et al. 1992). This is also true for larger field studies with entomopathogenic nematodes against D. v. virgifera (Toepfer et al. 2010a, c). We also confirmed that treatment effects against this pest are variable and may sometimes fail as it had been reported by Sutter et al. (1991); Gray et al. (1992); Furlan et al. (2006); Rauch et al. (2017); and others. For example, chlorpyrifos efficacies appeared so variable that statistical differences were difficult to detect, in fact only possible on female $D$. v. virgifera (Fig. 4). Failures of chlorpyrifos have been reported, such as by Sutter et al. (1991) from the USA, or by Furlan et al. the untreated infested control; error bars=SEM; \pm values on data labels $=\mathrm{SD}$; letters indicate significant differences to untreated control $\mathbf{a}$ and between treatments as per Tukey Post hoc multiple comparison tests after GLM

(2006) from Italy. The confirmed high variability in the efficacy of the tested products in our study was then addressed with regard to temporal changes in efficacy.

Therefore, we compared the temporal patterns of $D . v$. virgifera from treated plots of the 12 different experiments from 7 years to the temporal patterns from the untreated control plots. Interestingly, we found that all treatments continuously reduced $D$. v. virgifera without larger changes in their efficacies over time.

Only the temporal patterns of chlorpyrifos in our study suggest a slightly decreasing control efficacy with time, reflected in a slightly better control of early than late female larvae, although differences appeared small (see curve patterns in Fig. 5). Despite that, no such temporal differences were found when comparing the accumulative $25 \%, 50 \%$, $75 \%$, and peak emergence of adults compared to the patterns in the control (Table 3). Normally, chlorpyrifos is known to persist well in soils. Sutter et al. (1989) showed that chlorpyrifos in soil samples taken 158 days after application still caused $100 \%$ mortality of third-instar D. v. virgifera larvae. In Hungary, soil is usually moist during young vegetative maize stages, thus in the earlier period of larval feeding. During that period, chlorpyrifos may, despite its low solubility ( $2 \mathrm{mg} / \mathrm{l}$ water), still be dissolved enough to permit 


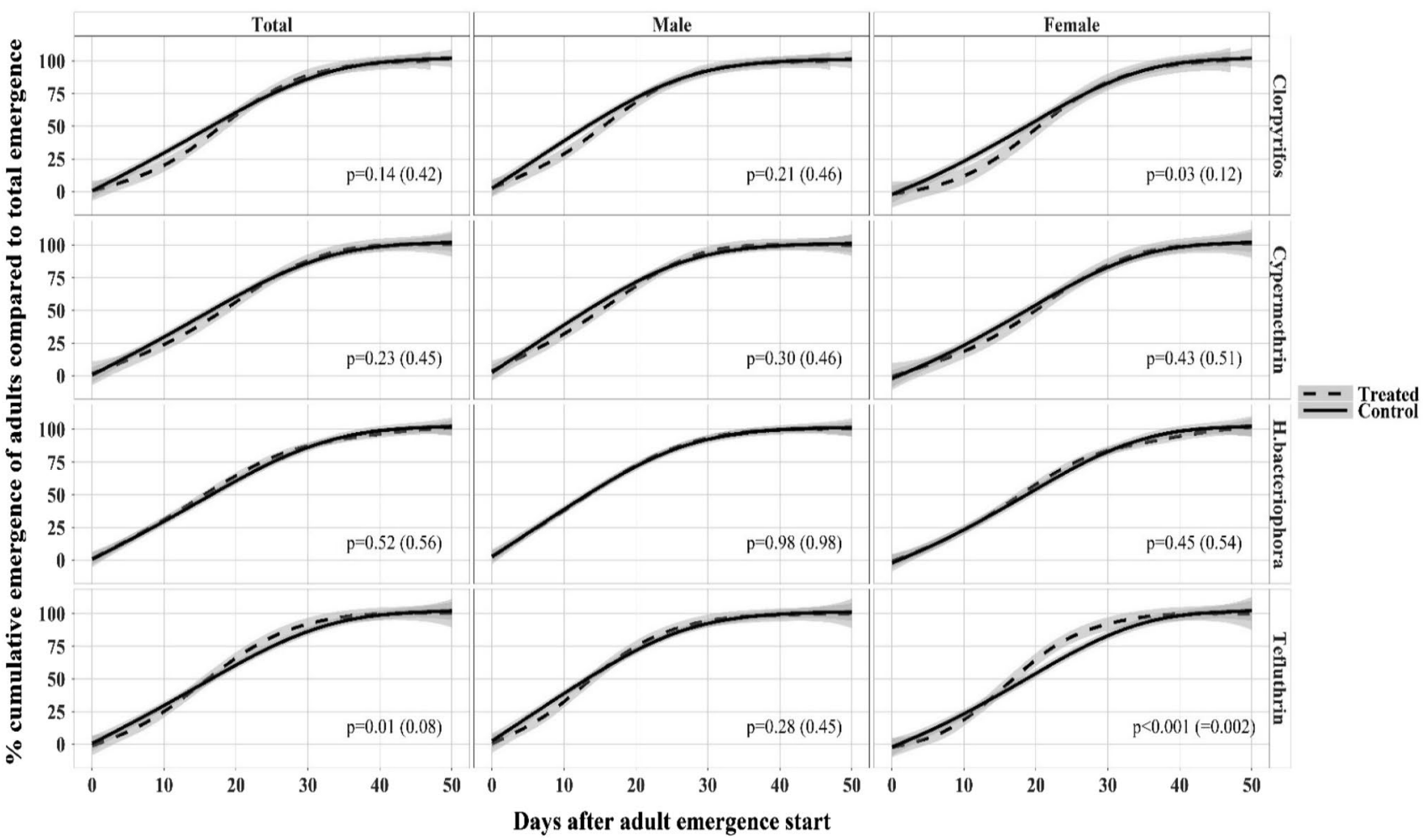

Fig. 5 Per cent cumulative emergence of Diabrotica v. virgifera adults over time in treatments and control, standardised as a proportion of their corresponding total cumulative emergence over a season in 4 to 12 maize fields in Hungary between 2010 and 2018. Loess

some vertical and horizontal movement of the insecticide in the root zone (Royal Society of Chemistry 1986; Sutter et al. 1989; Racke 1993). This may explain why chlorpyrifos was able to reduce early female larvae (Fig. 5). Later in the season, soil may become drier; thus, this pesticide may hydrolyse (Racke et al. 1996), and therefore, late female larvae may be comparatively less reached. Also, Sutter et al. (1991) argued that adequate soil moisture in the upper soil layers favours pesticide efficacy, and drought later in the season may be disadvantageous. Therefore, Sutter et al. (1991) reported occasionally delayed adult emergence due to chlorpyrifos, ethoprop, and carbofuran. Those patterns were suggested to be likely due to high efficacies in reducing early larvae soon after treatments, something not obviously reflected in our study results. As for other organophosphates, Boetel et al. (2003) reported occasionally delayed and flattened accumulative adult emergence slopes of $D . v$. virgifera and D. barberi in terbufos-treated plots. Chlorethoxyfos decreased the inflection point and slope of the adult emergence curve of male $D$. v. virgifera and delayed the maximum emergence period of females $D$. v. virgifera. (Time period elapsed before attaining the linear beetle emergence period.) Nevertheless, all those reported temporal effects of organophosphates as well as the slight effects found in smoothed trend lines plotted with $95 \%$ confidence levels; $p$ values at $<0.05$ represent a difference between the quasi-binomial GLM fit of a certain treatment $\times$ time and the control $\times$ time ( $p$ values in brackets are fdr-corrected using the Benjamini and Hochberg method)

our study are in their magnitude minor and may be of little relevance for the overall control efficacy of $D$. v. virgifera under field conditions.

Our study also included two common pyrethroid insecticides (cypermethrin and tefluthrin), but only tefluthrin appeared to have a slight temporal effect in pest control. It constantly reduced the male $D$. v. virgifera larvae. Then, interestingly, tefluthrin's comparative control efficacy slightly improved with time, reflected in a comparatively better control of late than early female larvae. This was also reflected in a time shift and change in steepness of the female as well as pooled-sex emergence curves (Fig. 5). As for the above-mentioned chlorpyrifos, tefluthrin's temporal effects seem so small that they are not reflected in changes in the 25 , $50,75 \%$, and peak cumulative adult emergence compared to the controls. Nevertheless, tefluthrin seems to be present and effective over a relatively long period in the soil under field conditions. Chapman et al. (1993) and Whiting et al. (2014) argued that the applied concentrations should remain, despite ongoing degradation, high enough for killing the pest larvae over time. Reasons for comparatively increasing control effects against female larvae with time remain hypothetical. But they may be due to exposure of female larvae to low dosage tefluthrin, and therefore sublethal and subsequently 
delayed lethal effects, as it had been reported for D. barberi (Michaelides et al. 1997). Branson (1987) showed a prolongated pre-hatch and longer post-hatch development time for females, resulting in an about 5 days later female than male adult emergence, the latter also been shown in our study for D. v. virgifera, and by Boetel et al. 2003 for female Diabrotica barberi.

Interestingly, no such time patterns were found for the other tested pyrethroid: cypermethrin. Also, cypermethrin appeared variable in controlling D. v. virgifera and failed in few experiments, as did tefluthrin. To our knowledge, there are no field studies addressing failures of cypermethrin in controlling $D$. v. virgifera larvae, and any reasoning would be highly speculative.

Heterorhabditis bacteriophora, as expected, successfully reduced larvae over time, regardless of sex. It is known that applied nematodes in maize fields persist due to propagation for several months (Kurtz et al. 2007; Pilz et al. 2014), although not as long as in crops with better vegetation cover (Pilz et al. 2014). However, our hypotheses that the propagation of the nematodes in the larvae as reported by Kurtz et al. (2009) would lead to a largely increasing comparative efficacy of this agent over time were not reflected in the temporal data of D. v. virgifera emergence under field conditions. It is known that nematodes can effectively kill first-instar larvae, but may have difficulties to reproduce in them due to the small size of those larvae (Kurtz et al. 2009). Propagation is better in the larger-, second-, and third-instar larvae potentially leading to an increasing control of pest populations in the soil as time passes. Indeed, in our study, nematodes were able to continuously reduce the pest larvae over time, even at their suspected larval population peak in the soil, indicating successful propagation. However, this propagation of nematodes seemed not to have been high enough to have a detectable additional positive effect in controlling larvae later in the season. Reason behind the lack of such a pattern remains hypothetical. They may be found in less successful propagation under field conditions than in the laboratory (Pilz et al. 2014), because e.g. saprophytes are decomposing the killed, although somewhat symbiotic-bacteria protected, larvae before nematodes can propagate, or that the offspring of the commercial mass-produced nematodes undergoes trait changes that slightly reduce their host inding and/or virulence under field conditions (Bilgrami et al. 2006). Nonetheless, it is encouraging that nematodes can well reduce the early $D$. v. virgifera larvae and continue to do so for the late larvae under field conditions.

In conclusion, our results suggest that commonly used pesticides as well as nematode-based novel biocontrol products can, in general, control D. v. virgifera larvae over their relatively long presence in the soil. The exception that chlorpyrifos slightly better reaches early female than late female larvae, and that the comparative relative efficacies of tefluthrin increased with time, is in their absolute differences hardly detectable. Therefore, the often observed inconsistent and fluctuating levels of efficacies of treatments may be due to other reasons, such as locally varying abiotic and environmental factors. This merits further investigations leading to larger data sets from diverse field situations.

\section{Author contributions}

ST and JK developed the projects. ST designed the trials. ST, SZT, and collaborators implemented the studies. SZT and MSZ conducted the analysis. SZT wrote the manuscript with support from all authors.

Acknowledgements Open access funding provided by Szent Istvan University (SZIE). This work was possible due to the hospitality of Government Office of Csongrad County District of Plant Protection and Soil Conservation Division in Hodmezovasarhely in Hungary. Field space and machinery were provided by the farmers Jancso Pal and Gyorgy Szrnka in the Kondoros area and by the Cereal Research Station of Szeged in the Mako, Kiszombor, and Szeged area. We like to thank Michael Glas and Peter Knuth (LTZ, Germany), Michael Zellner (LfL, Germany) as well as Ralf-Udo Ehlers (e-nema, Germany) for the support and for the scientific exchanges that have improved the experiments. We like to thank for the technical support from Ferenc Koncz and Rajmond Stuber (Hodmezovasarhely, Hungary), Andor Kiss (University of Godollo, Hungary), and Ferenc Kiraly (Szeged, Hungary). We like to thank Keith Holmes (CABI, Switzerland) for improving the manuscript.

Funding Most field studies were funded through public funds, such as the CTI Innovation Promotion Agency of the Federal Office for Professional Education and Technology of Switzerland, the Ministry for Rural Areas and Consumer Protection of the State of Baden-Wuerttemberg via the agricultural technology centre LTZ, and the Bavarian State Ministry of Food, Agriculture and Forestry StMELF via the Bavarian State Research Centre for Agriculture LfL. Few field experiments were funded by e-nema $\mathrm{GmbH}$ in Schwentinental in Germany. The data analyses were funded by a Hungarian Governmental PhD Scholarship and the Hungarian Higher Education Institutional Excellence Program (20430-3/2018/FEKUTSTRAT) of the Ministry of Human Capacities. The manuscript preparation and publishing were supported by the EFOP-3.6.3-VEKOP-16-2017-00008 project co-financed by the European Union and the European Social Fund.

\section{Compliance with ethical standards}

Conflict of interest All authors declared that they have no conflict of interest. There is no financial or other dependency between authors and any of the companies considered.

Ethical approval All applicable international, national, and/or institutional guidelines for the care and use of animals were followed. This article does not contain any studies with human participants or vertebrates performed by any of the authors. 
Informed consent Informed consent was obtained from all individual participants included in the study.

Open Access This article is licensed under a Creative Commons Attribution 4.0 International License, which permits use, sharing, adaptation, distribution and reproduction in any medium or format, as long as you give appropriate credit to the original author(s) and the source, provide a link to the Creative Commons licence, and indicate if changes were made. The images or other third party material in this article are included in the article's Creative Commons licence, unless indicated otherwise in a credit line to the material. If material is not included in the article's Creative Commons licence and your intended use is not permitted by statutory regulation or exceeds the permitted use, you will need to obtain permission directly from the copyright holder. To view a copy of this licence, visit http://creativecommons.org/licenses/by/4.0/.

\section{References}

Anonymous (1999) Evaluation of insecticides: Diabrotica v. virgifera. EPPO PP 1/212(1: 3)

Anonymous (2007) Efficacy evaluation of plant protection products: design and analysis of efficacy evaluation trials: PP 1/152(3). EPPO Bull 37:11-24

Babendreier D, Keller S, Romeis J (2006) New approaches for controlling the western corn rootworm. Agrarforschung 13:80-83 (in German)

Ball HJ, Weekman GT (1962) Insecticide resistance in the adult western corn rootworm in Nebraska. J Econ Entomol 55:439-441

Bazok R (2001) Istrazivanje biologije i ekologije Diabrotica virgifera virgifera LeConte - Novog clana entomofaune Hrvatske (Research on the biology and ecology of Diabrotica virgifera virgifera LeConte - new member of entomofauna in Croatia). $\mathrm{PhD}$ thesis, Zagreb. (in Croatian)

Benjamini Y, Hochberg Y (1995) Controlling the false discovery rate: a practical and powerful approach to multiple testing. J R Stat Soc 57:289-300

Bilgrami AL, Gaugler R, Shapiro-Ilan DI, Adams BJ (2006) Source of trait deterioration in entomopathogenic nematodes Heterorhabditis bacteriophora and Steinernema carpocapsae during in vivo culture. Nematology 8:397-409

Blandino M, Rigamonti I, Testa G (2016) Control of western corn rootworm damage by application of soil insecticides at different maize planting times. Crop Prot 93:19-27

Boetel MA, Fuller BW, Evenson PD (2003) Emergence of adult northern and western corn rootworms (Coleoptera: Chrysomelidae) following reduced soil insecticide applications. J Econ Entomol 96:714-729

Branson TF (1987) The contribution of prehatch and posthatch development to protandry in the chrysomelid, Diabrotica virgifera virgifera. Entomol Exp Appl 43:205-208

Branson TF, Krysan JL (1981) Feeding and oviposition behavior and life cycle strategies of Diabrotica: an evolutionary view with implications for pest management. Environ Entomol 10:826-831

Chapman RA, Harris CR (1990) Enhanced degradation of insecticides in soil: factors influencing the development and effects of enhanced microbial activity. Am Chem Soc Washington, DC 7:82-96

Chapman RA, Harris CR, Tolman JH (1993) Further comparison of the persistence in clay loam of single and repeated annual applications of some granular insecticides. J Environ Sci Heal Part B 28:151-170
Ciosi M, Toepfer S, Li H (2009) European populations of Diabrotica virgifera virgifera are resistant to aldrin, but not to methyl-parathion. J Appl Entomol 133:307-314

Cook E (2018) Eurostat 2018: Agriculture, forestry and fishery statistics 2018 Edition

Darnell SJ, Meinke LJ, Young LJ (2000) Influence of corn phenology on adult western corn rootworm distribution. Environ Entomol 29:587-595

Devare MH, Jones CM, Thies JE (2004) Effect of Cry3Bb transgenic corn and tefluthrin on the soil microbial community: biomass, activity, and diversity. J Environ Qual 33:837-843

Ehlers RU (2003) Entomopathogenic nematodes in the European biocontrol market. Commun Agric Appl Biol Sci 68:3-16

Ehlers RU, Hiltpold I, Kulhmann U, Toepfer S (2008) Field results on the use of Heterorhabditis bacteriophora against the invasive maize pest Diabrotica virgifera virgifera. Insect Pathog insect Parasit nematodes 31:332-335

Faraway J (2004) Linear models with R. Chapman \& Hall, Boca Raton

Fisher JR (1984) Comparison of emergence of Diabrotica virgifera virgifera from cut and uncut corn plants in artificial and natural infestations. J Kansas Entomol Soc 57:405-408

Furlan L, Canzi S, di Bernardo A, Edwards CR (2006) The ineffectiveness of insecticide seed coatings and planting-time soil insecticides as Diabrotica virgifera virgifera LeConte population suppressors. J Appl Entomol 130(4):85-490

Godfrey LD, Turpin FT (1983) Comparison of western corn rootworm (Coleoptera: Chrysomelidae) adult populations and economic thresholds in first-year and continuous cornfields. J Econ Entomol 76:1028-1032

Gray ME, Felsot AS, Steffey KL, Levine E (1992) Planting time application of soil insecticides and western corn rootworm emergence: implications for long-term management programs. J Econ Entomol 85:544-553

Gray ME, Sappington TW, Miller NJ (2009) Adaptation and invasiveness of western corn rootworm: intensifying research on a worsening pest. Annu Rev Ecol 54:303-321

Hammack L, French BW (2007) Sexual dimorphism of basitarsi in pest species of Diabrotica and Cerotoma (Coleoptera: Chrysomelidae). Ann Entomol Soc Am 100:59-63

Kergunteuil A, Rasmann S, Bakhtiari M (2016) Biological control beneath the feet: a review of crop protection against insect root herbivores. Insects 7:70

Krysan JL, Miller TA (1986) Methods for the study of pest Diabrotica. Springer, New York, p 260

Kurtz B, Toepfer S, Ehlers RU, Kuhlmann U (2007) Assessment of establishment and persistence of entomopathogenic nematodes for biological control of western corn rootworm. J Appl Entomol 131:420-425

Kurtz B, Hiltpold I, Turlings TCJ (2009) Comparative susceptibility of larval instars and pupae of the western corn rootworm to infection by three entomopathogenic nematodes. Biocontrol 54:255-262

Levine E, Oloumi-Sadeghi H (1991) Management of diabroticite rootworms in corn. Annu Rev Entomol 36:229-255

Meinke LJ, Siegfried BD, Wright RJ, Chandler LD (1998) Adult susceptibility of Nebraska western corn rootworm populations to selected insecticides. J Econ Entomol 91:594-600

Meinke LJ, Sappington TW, Onstad DW (2009) Western corn rootworm population dynamics. Agric For Entomol 11:29-46

Michaelides PK, Cleverly AL, Wright DJ (1997) Sub-lethal effects of tefluthrin on Diabrotica undecimpunctata howardi: plant protection and larval development. Crop Prot 16:423-429

Miller N, Estoup A, Toepfer S et al (2005) Multiple transatlantic introductions of the western corn rootworm. Science 310:992 
Moeser J, Hibbard BE (2005) A synopsis on the nutritional ecology of larvae and adults of Diabrotica virgifera virgifera in the New and Old World. In: Vidal S, Kuhlmann U, Edwards CR (eds) Western corn rootworm: ecology and management. CABI, Wallingford, p 320

Nowatzki TM, Tollefson JJ, Calvin DD (2002) Development and validation of models for predicting the seasonal emergence of corn rootworm beetles in Iowa. Environ Entomol 31:864-873

Pereira AE, Wang H, Zukoff SN (2015) Evidence of field-evolved resistance to bifenthrin in western corn rootworm populations in western Nebraska and Kansas. PLoS ONE 10:e0142299

Pilz C, Keller S, Kulhmann U (2009) Comparative efficacy assessment of fungi, nematodes and insecticides to control western corn rootworm larvae in maize. Biocontrol 54:671-684

Pilz C, Toepfer S, Knuth P et al (2014) Persistence of the entomoparasitic nematode Heterorhabditis bacteriophora in maize fields. J Appl Entomol 138:202-212

R Development Core Team (2018). R: A language and environment for Computing, statistical computing. R Foundation for Statistical Vienna, Austria. URL http://www.R-project.org

Racke KD (1993) Environmental fate of chlorpyrifos. Rev Environ Contam Toxicol 131:1-150

Racke KD, Steele KP, Yoder RN (1996) Factors affecting the hydrolytic degradation of chlorpyrifos in soil. J Agric Food Chem 44:1582-1592

Rauch H, Steinwender BM, Mayerhofer J (2017) Field efficacy of Heterorhabditis bacteriophora (Nematoda: Heterorhabditidae), Metarhizium brunneum (Hypocreales: Clavicipitaceae), and chemical insecticide combinations for Diabrotica virgifera virgifera larval management. Biol Control 107:1-10

Rice ME (2004) Transgenic rootworm corn: assessing potential agronomic, economic, and environmental benefits. Plant Heal Prog 5(1): 12

Royal Society of Chemistry (1986) Agrichemicals handbook, 5th edn. Unwin brothers publishing, Old Woking

Ruppel RF, Russell HL, Jennings SJ (1978) Indices for projecting emergence of corn rootworm adults in Michigan. J Econ Entomol 71:947-949

Singh P, Moore RF (1999) Handbook of insect rearing. Elsevier, Amsterdam

Sutter GR, Branson TF, Fisher JR et al (1989) Effect of insecticide treatments on root damage ratings of maize in controlled infestations of western corn rootworms. J Econ Entomol 82:1792-1798

Sutter GR, Fisher JR, Elliott NC, Branson TF (1990) Effect of insecticide treatments on root lodging and yields of maize in controlled infestations of western corn rootworms. J Econ Entomol 83:2414-2420
Sutter GR, Branson TF, Fisher JR, Elliott NC (1991) Effect of insecticides on survival, development, fecundity, and sex ratio in controlled infestations of western corn rootworm. J Econ Entomol 84:1905-1912

Szalai M, Komáromi JP, Bažok R, Barčić JI, Kiss J, Toepfer S (2011) Generational growth rate estimates of Diabrotica virgifera virgifera populations (Coleoptera: Chrysomelidae). J Pest Sci 84:133-142

Toepfer S, Kuhlmann U (2006) Constructing life-tables for the invasive maize pest Diabrotica virgifera virgifera (Coleoptera: Chrysomelidae) in Europe. J Appl Entomol 130:193-205

Toepfer S, Peters A, Ehlers RU, Kuhlmann U (2008) Comparative assessment of the efficacy of entomopathogenic nematode species at reducing western corn rootworm larvae and root damage in maize. J Appl Entomol 132:337-348

Toepfer S, Burger R, Ehlers RU (2010a) Controlling western corn rootworm larvae with entomopathogenic nematodes: effect of application techniques on plant-scale efficacy. J Appl Entomol 134:467-480

Toepfer S, Ehlers RU, Kuhlmann U, Turlings TCJ (2010b) Factors influencing the biological control of the larvae of the corn pest Diabrotica virgifera virgifera by nematodes. In: 428 edn. Julius Kühn Institut, Bundesforschungsinstitut für Kulturpflanzen, Quedlinburg, p 213

Toepfer S, Hatala-Zseller I, Ehlers RU (2010c) The effect of application techniques on field-scale efficacy: can the use of entomopathogenic nematodes reduce damage by western corn rootworm larvae? Agric For Entomol 12:389-402

USDA (2018) Crop production 2018 summary. USDA, National Agricultural Statistics Service NASS, Washington, D.C., p 44

van Rozen K, Ester A (2010) Chemical control of Diabrotica virgifera virgifera. J Appl Entomol 134:376-384

Wesseler J, Fall EH (2010) Potential damage costs of Diabrotica virgifera virgifera infestation in Europe-the "no control'scenario. J Appl Entomol 134(5):385-394

Whiting SA, Strain KE, Campbell LA (2014) A multi-year field study to evaluate the environmental fate and agronomic effects of insecticide mixtures. Sci Total Environ 497-498:534-542

Wright RJ, Scharf ME, Meinke LJ (2000) Larval susceptibility of an insecticide-resistant western corn rootworm population to soil insecticides: laboratory bioassays, assays of detoxification enzymes, and field performance. J Econ Entomol 93:7-13

Publisher's Note Springer Nature remains neutral with regard to jurisdictional claims in published maps and institutional affiliations. 